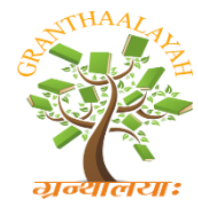

INTERNATIONAL JOURNAL OF RESEARCH GRANTHAALAYAH A knowledge Repository

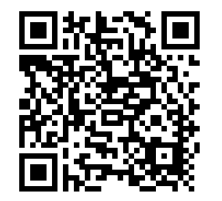

Management

\title{
ENTREPRENEURIAL CHARACTERISTICS AND COMPETENCIES AS DETERMINANTS OF CORPORATE PERFORMANCE: A STUDY ON SMALL ENTERPRISES IN MOGADISHU, SOMALIA
}

\author{
Abdullahi Mahadalle ${ }^{1}$, Dr. Burcin Kaplan ${ }^{2}$ \\ ${ }^{1}$ MS Student, Institute of Social Sciences, Istanbul Aydin University, Besyol Mahallesi, Inonu \\ Cd. No: 38, 34295 Kucukcekmece, Istanbul, Turkey \\ ${ }^{2}$ Assistant Professor, Institute of Social Sciences, Istanbul Aydin University, Besyol Mahallesi, \\ Inonu Cd. No: 38, 34295 Kucukcekmece, Istanbul, Turkey
}

DOI: https://doi.org/10.5281/zenodo.583915

\begin{abstract}
The encouraging outcomes of organizational success, emerging from productive entrepreneurship has led academic and administrative attention on concepts of entrepreneurial competencies and entrepreneurial characteristics in the last few decades. In Somalia particularly, the women have been found to be playing a significant role in the small business sector, despite the several challenges faced by them. The present research aims at assessing the effect of entrepreneurial competencies and entrepreneur's demographic and personal characteristics on business performance among initial stage entrepreneurs. Further, it also aims at spotting the main challenges encountered by the women entrepreneurs involved in Small business in Somalia. The study adopted extensive relevant literature reviews on the studied variables and drawing conclusions based on the conducted reviews. The reviewed studies showed that entrepreneurial characteristics and entrepreneurial competencies are positively related to overall business performance. Further, through the studies, the study also supports the claim that Somali women entrepreneurs make a significant contribution to the small-scale businesses in Somalia but faced several challenges that must be catered to as an urgency.
\end{abstract}

Keywords: Entrepreneurial Characteristics; Entrepreneurial Competencies; Somali Women Entrepreneurs; Small-Scale Business.

Cite This Article: Abdullahi Mahadalle, and Dr. Burcin Kaplan. (2017). "ENTREPRENEURIAL CHARACTERISTICS AND COMPETENCIES AS DETERMINANTS OF CORPORATE PERFORMANCE: A STUDY ON SMALL ENTERPRISES IN MOGADISHU, SOMALIA." International Journal of Research - Granthaalayah, 5(5), 243-254. https://doi.org/10.5281/zenodo.583915. 


\section{Introduction}

As the interest in entrepreneurship and business has improved significantly in recent decades, and there is a little or no sign of concern to the literature which is studying the relating problems and issues faced in small business particularly in somalia; this piece provides an extensive overview of the entrepreneurial characteristics and competencies as determinants of business performance by reviewing the relevant literature to address the effect of entrepreneurial competencies on business performance among early stage entrepreneurs. It also focuses the entrepreneurial competencies and the performances of the impact of entrepreneur's personal characteristics and demographic characteristics on firm's performance under the mediating role of entrepreneur orientation. The literature glimpses the role of Somali women entrepreneurs in small scale businesses as they have been found to be playing a significant role in the small business sector. At last, it determines some factors which are influencing the women in small scale business.

\section{The Notion of Small Business}

According to Nair et al. (2012), small businesses are an efficient process in alleviating poverty. It enhances the employment opportunities in most developing economies. Many researchers have found that most of the small-scale businesses have created the job opportunities and the selfemployment opportunities. Small enterprises are acts as the important contributor to enhancing economic growth, rural economic activity, poverty alleviation and social justice.

Small and medium enterprises are those enterprises which have a minimum number of employees and work on small scale. Many of the researchers have found that the small business has increased the gross domestic product (GDP) rate of the country. Small businesses hold an important place to enhance the growth of the country. It also provides the employment opportunities for those who are unemployed in the rising economy (Jasra et al.,2011).

Clark (2003) defined the small business as a small organization and small governmental authority or jurisdiction. A small-scale business is an independently owned concern, and the independent person operates it. Small business is not dominant in the operation field. Moreover, it satisfies many additional criteria which have established by the small business administration (SBA).

\section{The Impact of Entrepreneurial Competencies on Corporate Performance Among Early-Stage Entrepreneurs}

According to Barazandeh et al. (2015), export rates of entrepreneurs are varied among the early stage entrepreneurs. Entrepreneurial competencies are created the positive impact in the business performance. The personalities of entrepreneurs are far more different from the early stage entrepreneurs. Nowadays most of the entrepreneurs are very effective in management skills and knowledge, and this has enhanced their business in high level. In addition to this, the entrepreneurs have undergone various training programs to develop their skills and knowledge, but in past days the early stage entrepreneurs had not involved in the training programs to develop their business. 
Wickramaratne, Kiminami, and Yagi (2014) studied the entrepreneurial orientations and entrepreneurial competencies of tea manufacturing firms. Many researchers have found that there is a positive relationship between the entrepreneurial competencies and the firm performance. The nature of entrepreneurial competencies is improving the entrepreneurship. Opportunity, strategic competency, organizing, relationship competency, commitment competency and the conceptual competencies are some of the competencies which are effectively handled by the entrepreneurs among the early stage entrepreneurs. Work experience has created the positive impact in the business performance. Moreover, the skills and abilities of an entrepreneur could be improved through work experience. Authors have pointed that the self- assessed competencies of the entrepreneur have a positive relationship with the growth of the firm.

Networking acts as the major factor for the entrepreneurs, and it has enhanced the performance of the business growth. Networking activities aimed to provide the assistance to entrepreneur. These networking activities are in the form of shared experiences and role models, information, support, and motivation. Development of inter-organizational network has influenced the performance of the entrepreneurs which in turn produces the effective growth of small business. Entrepreneurial competencies have enhanced the performances of business by using the networking process (Hoyos-Ruperto et al., 2013).

Zulkifli and Rosli (2013) studied the entrepreneurial orientation and the business success of Malay entrepreneurs. The religious belief of early stage entrepreneurs affected the business performance in past days. The performance and the entrepreneurial competencies of early stage entrepreneurs are more different than entrepreneurs in today's field. The environmental hostility acted as the significant moderator between the entrepreneurial orientation and the profitability firm.

Competency of entrepreneur acts as the effective tool for predicting the performance of the firms. The entrepreneur can use attitudes and skills in which it leads to attaining the successful performances of the small business. The technical competency of entrepreneur has varied from day to day of which it also leads to produces the effective performance among the early stage entrepreneurs. Communication competencies have played an important role in the entrepreneurship. Many practices and activity programs are used to enhance the entrepreneurial activity which can also help the effective program to foster the entrepreneurship. Authors have pointed that the entrepreneurial competency has provided the policy makers and the stakeholder of which it contains the important predictors of venture success (Izquierdo, Deschoolmeester, and Salazar, 2005).

\section{The Entrepreneurial Competencies and The Performance of SME's}

According to Bendary and Minyawi (2015), psychological contracting acts as the mediator of the relationship between the performance of small-scale and medium enterprises and the entrepreneurial competencies. Authors have used the six areas of competencies which are positively related to the performance of the business. Some of them are relationship competency, opportunity competency, conceptual competency, organizing competency, strategic and commitment competency. In addition to these, the entrepreneurial competencies are engaged in three important roles such as the entrepreneurial role, the technical role, and the managerial role. 
These factors have enhanced the growth of the small-scale and medium businesses. Strong networking has used to establish the sustainable competitive advantage in the small and medium business. Authors have pointed that the delivery competency, transformation competence, and relationship competency are some of the capabilities which are critical for outsourcing provider's success of the business process.

Lazar and Paul (2015) studied the entrepreneurial competencies in a business enterprise. Entrepreneurial competencies have associated with some of the factors such as attitudes, beliefs, personality, mindset and the behavioral tendencies. These entrepreneurial competencies are positively associated with the performances of the firm and the competitiveness. Opportunity competency, organizing competency, conceptual competency, technical competency, and behavioral competency are the five entrepreneurial competencies which the entrepreneurs needed to be well competent in the business environment to enhance the sustainable competitive advantage. Moreover, the organizing competencies are like the managerial competencies. In this way, the coordinating, monitoring and organizing the internal and external resources are some of the significant factors which are closely associated with the organizing competencies which in turn produces the effective performance of small and medium enterprises. Apart from this sector, technical competency involves possessing knowledge of tools or instruments, mastery of tasks and the work content are created the effective performance to successful business growth.

Competencies of entrepreneurs have led a business more successful, and it provides the sustainable competitive advantage. Valuable skill, knowledge, and the ability to take the risk, birth and survival are some of the factors which are closely associated with the entrepreneurial competencies which also have produced the successful performance of the small and medium business. Personal qualities, self-confidence, and innovativeness, are some of the terms which are positively associated with the entrepreneurial competencies. Some of the competencies which have both the direct and the indirect influence on the performance of small and medium enterprises are an opportunity, learning, commitment, operational and personal competencies. Apart from these factors, the entrepreneurial competency refers to ethical, conceptual, and strategic competencies which are produced the business success in small and medium enterprises. Many researchers have found that the entrepreneurial competencies are related to the performance of venture (Tehseen and Ramayah, 2015).

According to Mohamad and Sidek (2013), entrepreneurial competencies mediate the relationship between the growth of microfinance and the small businesses. Some of the entrepreneurial competencies are lifestyle improvement, expansion of the business facility, adoption of better technology and the problem-solving capability. These are used to improve the successful performance outcomes of small and medium enterprises. Moreover, the training and the development program has helped to attain the growth of business. Authors have pointed out some of the basic characteristics such as generic, motivation, problem solving and decisionmaking skill and knowledge. These characteristics are positively associated with the survival of the small and medium business. A wide range of training has used to improve money management skills, attitudes, management of risk, quality life, and communication skills. Entrepreneurial competencies have played an effective role in the growth of the micro and medium business. 
Sarwoko et al. (2013) studied about the entrepreneurial characteristics and competencies as determinants of business performance in small and medium enterprises. Education, value of personal, experience in work, a support network of professional, psychological factors and attribute are some of the factors associated with the entrepreneurial characteristics which are used to enhance the business growth. Some of the entrepreneurial competencies are strategy competency, commitment competency, opportunity competency, conceptual competency, relationship competency, and the organizing competency. Strategy competency has used to develop the vision and strategy. Commitment demonstrates a strong motivation to make drive and dedication to business growth. Conceptual competency has used to improve the ability to weigh risk, and it also induces the capacity to take the risk. Opportunity competency can capture and identify the need of the customer. Communication and interpersonal skills are depending upon the relationship competency. Finally, the organizing competency can direct, planning, developing and preparing the budget. These factors of entrepreneurial competencies have produced the successful performance outcomes in small and medium enterprises.

Laguna, Wlechetek and Talk (2012) studied the competencies of managers and their business success. Managerial competencies are considered as the significant predictors of business success. In this way, these managerial competencies are acted as the mediator between the general competencies and the success of small and medium enterprises. Managerial competencies have helped to characterize the person who manages the team of workers. Knowledge, skills, and behavioral patterns are some of the characteristics associated with the managerial competencies which have contributed the successful fulfillment of the managerial performances. Apart from these, the general competencies refer to the wider characteristics of personality, skills and values and behavioral patterns. It has used the creative approach to solving the problems. In addition to this, the social skills are used in many critical situations to reduce the difficulties in order to improve the performances of small and medium enterprises.

Entrepreneurial competencies have played a significant role in the organizational competence and the competitive scope of small-scale and medium enterprises. It has a direct effect on the performance of the firm Sanchez (2012). Entrepreneurial competencies are nothing but the characteristics of people which is used to enhance the work effectiveness and performances. A managerial competency has possessed the greater attention among other competencies. This competency has demonstrated the persons' actions and behavior. Further, it is related to the dynamic characteristics of competitiveness. The author finally has concluded that the entrepreneurial competencies are positively related to the performance of the firm.

\section{The Effect of Entrepreneur's Demographic and Personal Characteristics on Organization's Performance under the Mediating Role of Entrepreneurs}

According to Abdulwahab and Al-Daman (2015), entrepreneurs' characteristics have created the positive impact in the firm performances. Some of the entrepreneurial characteristics are personal traits and skills which are the personal characteristics. These factors have constituted the competency of entrepreneurs to venture a success. Need for achievement has possessed the strong relation with the entrepreneurship. It is considered as the important characteristics of entrepreneurs. Need for achievement is defined as the people who want to attain the strong desire for success. Many of the researchers have found that the need for achievement is included in the 
psychological trait which drives the entrepreneurs to attain high standards. Further, this strategy leads the entrepreneurs towards success. Apart from this category, self-confidence is another important personal characteristic of the entrepreneurs which are positively influenced the performances of the small and medium business. High level of believing about them so called as the self-confidence which has led the entrepreneurs towards success. Pro-activeness or imitativeness is nothing but the forward-looking perspectives which are focusing on introducing new products to change the business environment. It is also involved in the characteristics of entrepreneurship. At last, independence, responsibility, risk taking prosperity and experience are some of the personal characteristics which are of the entrepreneur's characteristics. These characteristics are enhanced the business growth in the higher level.

Aliyu, Rogo, and Mahmood (2015) studied the entrepreneurial orientation, knowledge management and business performance in the role of organizational culture. Entrepreneurial orientation (EO) has played a significant role in the growth of an organization in the competitive environment. Entrepreneurial orientation is the administrative and the decision-making activities which would lead to some new developments in the small business. Moreover, the entrepreneurial orientation has created the positive impact in the organizational performance of small and medium enterprises. Knowledge, skills, adapting to an organizational environment, flexibility and the learning competency are some of the factors associated with the personal characteristics which are also played the role of entrepreneur. These are improved the sustainable competitive advantage in the small-scale business. There is a significant association between the entrepreneurial orientation and the performance of the enterprises.

Gender, age, education, and marital status are some of the demographic characteristics of entrepreneurs which are positively associated with the performance of the small business. There is a significant relationship between the people's demographic and the compliance behavior of the tax. In addition to these, the demographic variables such as employment status, occupation, ethnicity, tax return filing experience, and course. Older taxpayers are more compliant than the younger tax payers. Age plays a crucial role in compliance. Gender is considered as one of the vibrant factors that affect the attitude of tax compliance and tax payer's attitudes (Antwi, Inusah, and Hamza, 2015).

Isaga (2015) studied the owners- the demographic characteristics of the manager and the growth of small and medium enterprises. The factors like age, family background, education, and the working experience are some of the demographic factors which are positively associated with the entrepreneurial characteristics. These factors have contributed to the success of entrepreneurs. Education is the major factor of human capital. This element is deemed as the foundation and the source of skills, self-confidence, and overall knowledge. Several studies have shown that there is a positive relationship between the education of the entrepreneurs and the growth of the small and medium enterprises. Many researchers have learned that the education is not a relevant factor in determining the small business growth. Apart from these terms, management experience, the entrepreneurial experience, and the industrial related experience are some of the important experience associated with the successful performance of the business growth. Experienced entrepreneurs have the tendency to direct the firms in a more effective way because of their prior experience from handling enterprises has provided a set of trainings in many aspects for acquiring many entrepreneurial opportunities in a successful manner. In addition to 
this, age is considered as the important demographic characteristics which have influenced the advancement of small-scale and medium enterprises. Inverted U-shaped association is maintained in the age of entrepreneurs and the growth of the small and medium enterprises. Knowledge necessary to soundly run a business can be gained through observation to another one, or it can be acquired or motivated from the family background. The entrepreneur comes from the entrepreneurial family has achieved greater success in business when compared to others.

Miao (2015) studied the individual traits and entrepreneurial intentions regarding the mediating role of entrepreneurial self-efficacy and the need for cognition. The individual trait has played an effective role in the entrepreneurship. Conscientiousness, Openness to experience, emotional stability, and the extraversion are the four factors big five personality traits. These are the significant predictors of entrepreneurial intention. These personality characteristics are created the positive impact in the performance of the business growth. These personality characteristics are significantly associated with the entrepreneurial characteristics. Many researchers have found that the biological factors are affected the activity of entrepreneurs which in turn reduces the successful performance of an organization. Self-efficacy of the entrepreneurs mediates the relationship between the individual behavior and the intention of entrepreneurs. Moreover, the individual traits are associated with the emotional intelligence, cognitive ability, risk propensity, proactive personality, and rebelliousness. These individual traits are related to the entrepreneurial intentions and the entrepreneurial self-efficacy. The entrepreneurial self-efficacy is created the positive impact in the entrepreneurial intentions. Cognitive psychology has provided the strong implications for the intention of entrepreneurs. Personal characteristics of entrepreneurs have predicted the probability new venture success and failure.

Bakar, Mahmood, and Ismail (2014) studied the combined effect of knowledge management and entrepreneurial orientation on the performance of small and medium enterprises. Entrepreneurial orientation is the valid concept, and it has played an effective role to improve the organizations by decision making across multiple organizational contexts. The personal characteristics such as leadership style, creative or innovative knowledge, and skill are closely associated with the entrepreneurial characteristics. This has created the positive impact in the performance of the small business. Many researchers have found that the knowledge management scale has helped in the small business to enhance sustainable competitive advantage. Authors have found that there is a mediating effect of entrepreneurial orientation on the relationship between the knowledge management and the business performance. Hence the entrepreneurial orientation acts as the mediator between the knowledge management and the firm performances. Gender, education, status, experience, the number of employees and the types of operation are some of the characteristics associated with the entrepreneurial characteristics. They also have helped to attain the successful performances outcomes of an organization.

Chuluunbaatar et al. (2011) studied the entrepreneurial orientation start-up process on the role of social capital and the social, economic condition. Some of the personal characteristics are controlled locus, the ability of risk-taking, the motivation of achievement, the style of problemsolving, creativity, behavior, and working value. These characteristics are related to the entrepreneurs, and these factors have created the positive impact in the performances of the small business. Entrepreneurial attitudes, intention, and the behavior are closely related to each other, 
and it can be traced using the models of intention. Several researchers have found that the intention acts as the mediator between the effects of attitudes and the behavior. These are related or dependent on personality and the environment. In addition to this, the personality of entrepreneurs strongly depends on upon the family, social environment, and the culture. Moreover, the entrepreneurs have reflected the personality of an individual, insight and understanding, and justification of their ability. These behavioral tendencies lead the effective leadership acquisition, interpersonal competencies, and the persuasive competencies. Five major factors are used to measure a one's personality characteristics. The personality characteristics, for instance, act as the predictors of the entrepreneurial intentions. The neuroticism, extraversion, agreeableness, openness to experience, and the conscientiousness are the five broad traits of personality characteristics.

Many demographic approaches have used to analyze the personality characteristics of an individual. This has determined the spirit of the entrepreneurs and it helps to distinguish the entrepreneurs from others. Demographic characteristics have focused some of the variables such as the background of the family, previous experience of work in a start-up, the status of a socioeconomic factor, age, level of education and birth order. These factors have helped to achieve the successful performance outcomes of the small business. Ownership type, marital status, and income are some of the demographic variables which are created the positive impact in the entrepreneurial attitudes. Perseverance, hard work, ability to take the risk, dynamism, creativity, innovative, self-confidence and the excellent time perception are some of the personal characteristics of entrepreneurs. These characteristics have enhanced to achieve the successful performance in their business. Authors have pointed that the level of entrepreneurial attitudes increases as the increase in age, income, ownership type and marital status (Tamizharasi and Panchanatham, 2010).

\section{The Role of Somali Women Entrepreneurs in Small -Scale Businesses}

According to Hundera (2014), women involvement in the micro and small-scale enterprises have increased the economic development of the country. Somali women entrepreneurs have played an important role in reducing the poverty of Somalia. They are like an active participant in the many development processes. Several strategies have adopted by the women in Somalia to enhance the entrepreneurial start-ups. They have created the good social network to enhance their business activity. Some of the Somali women have attained the specific business skills and experience in the small-scale businesses. Moreover, they have the knowledge to promote their business into international level. Somali women have earned their living by involving in the small business.

Iyitola and Azuh (2014) studied about the women entrepreneurs as small, medium enterprise (SME) operators and their roles in socio- economic development. Somali Women have engaged in the financial and economic sector. They have acted as the owners of their small-scale business. Moreover, they also have engaged in the productivity sector, and they succeed in high level. Women involvement in small-scale business has enhanced the economic development of the country. Many of the Somali women have generated the employment for those who are unemployed. Authors have pointed that the women have played a traditional role in the typical 
family setting which also has allowed women to undertake more functional roles within the society. Somali women entrepreneurs have created an impact on the small-scale businesses.

Somali women possess higher involvement in the clothing sector than other nationality. Many of the Somalis have interested to make their traditional clothes, and they have become wholesalers of the small-scale businesses. The operating modes of Somali women are far different from other women entrepreneurs. In this way, the Somali women are committed not only with the clothing sector but also in the grocery sector. Many of the restaurants have successfully run by the Somali women entrepreneurs (Kalitanyi and Visser, 2014).

Ali (2013) studied the challenges and constraints faced by the Somali women entrepreneurs in Benadir region. Somali women have played a vibrant role in the economic development of Somalia. Many of the Somali women have started the small-scale businesses in both the formal and informal sector. Small enterprises are acted as the key component for Somali women to develop their economic conditions. Somali women are playing the major role in their family. They have succeeded to start their own business and hence they were facing many problems in their business sector. Some of the Somali women were good in financial management of small scale businesses. In this way, many women are committed as the active partners with their spouses to run their small-scale business.

\section{Factors Influencing Women in Small-Scale Businesses}

According to Chitra et al. (2014), personal factors have influenced the performances of the women in the small-scale businesses. In this way, the social support, networking clarity, personal motives, and technology are created the positive impact in the successful performance of the women entrepreneurs. Some of the personal qualities such as the creativity or innovation, perseverance, balancing of life and work, family members support, self-efficacy, optimism, pursuing the new opportunities, techniques related to marketing, taking risk and capability of handling stress. These qualities are positively associated with the women entrepreneurs to enhance the performance of the small-scale enterprises.

Ongachi and Bwisa (2013) studied the factors influencing the growth of women-owned micro and small enterprises. Lack of finance and skill, the inability of performing the multiple roles and lack of experience are some of the factors which are distressing the growth of women entrepreneurs negatively in the small-scale business. Moreover, the women entrepreneurs have more financial demand on social which compete with the business capital. Further, this leads to capital diversion away from the needs of business. Initial capital accessibility has created the negative impact in the growth of women entrepreneurs in small scale business.

A strong family support system has positively influenced the women in the small-scale businesses. Some of the factors which have influenced the women in small business are business planning, social network, and professional development. These factors have influenced the ability of women. Entrepreneurial innovation has played a vital role in business survival. Lack of financial resources, external information weakness, and a shortfall in management expertise are the factors which limit the competitiveness of women in small scale business. Raw materials acquisition, development of new product, production process and the marketing stand out are 
some of the significant factors which are influencing the survival of women businesses. Moreover, women entrepreneurs are facing a lot of obstacles such as the high of the tax system, changing legislations, lack of accessing the high-interest rate, administrative controls, and the lack of financing. At last, fulfilling the requirements of the bank is considered as the major challenge for the women entrepreneurs in small scale businesses (Chea, 2008)

Yen, Teoh, Choy, and Chong (2007) studied the factors influencing the performance of women entrepreneurs in Malaysia. The performance of women entrepreneurs is influenced by their ability, motivation, and the opportunity. The gender differences in performances of the business have created the complexity for the women entrepreneurs. Business skill, personal goals of the women, different strategy, and experience are some of the factors which are positively influenced the performance of the women entrepreneurs in small business. In addition to this, the social learning theory, level of education, organization membership and environmental aspects are the factors which have influenced the performance of the women in small business.

The belief of cultural and religion, preference, and capabilities of entrepreneurship, environment, and technology, are some factors which have influenced the effectiveness and the performance of the women entrepreneurs in small scale industry. In addition to this, the gender differences are considered as the major factors which are created the negative impact to the women entrepreneurs in small business (Olabisi, Yusuff, Olagbemi and Atere, n.d). Authors have pointed out some of the factors which are influenced the performances of women in small businesses are business age, operating location, structure of business, financing amount, and employees.

\section{References}

[1] Nair R. et al. (2012), Understanding Key Impediments to Small Businesses in South Pacific Island Nations: A Case of Fiji, The Journal of Global Business Management, 8(1).

[2] Jasra M. J. et al. (2011), Determinants of Business Success of Small and Medium Enterprises, International Journal of Business and Social Science, 2(20).

[3] John F. Clark (2003), the Tower Law Sourcebook: Covering Federal Environmental Regulation of Communication Facilities, Pike \& Fischer- A BNA Company.

[4] Barazandeh M. et al. (2015), Investigating the Effect of Entrepreneurial Competencies on Business Performance among Early Stage Entrepreneurs Global Entrepreneurship Monitor (GEM 2010 Survey Data), Journal of Global Entrepreneurship Research, 5(18).

[5] Wickramaratne A., Kiminami A. and Yagi H. (2014), Entrepreneurial Competencies and Entrepreneurial Orientation of Tea Manufacturing Firms in Sri Lanka, Asian Social Science, 10(18).

[6] Hoyos-Ruperto D M et al. (2013), networking: A Critical Success Factor for Entrepreneurship, American Journal of Management, 13(2).

[7] Zulkifli M. R. and Rosli M. N. (2013), Entrepreneurial Orientation and Business Success of Malay Entrepreneurs: Religiosity as Moderator, International Journal of Humanities, and Social Science, 3(10).

[8] Izquierdo E., Deschoolmeester D. and Salazar D. (2005), The Importance of Competencies for Entrepreneurship: A View from Entrepreneurs and Scholars' Perspective, retrieved on January 4, 2016 from https://www.google.co.in/url?sa=t\&source=web\&rct=j\&url=http://www.espae.espol.edu.ec/desca rgar-documento/87-no-1-b-the-importance-of-competencies-forentrepreneurship\&q=journal\%20- 
$\% 20$ effect $\% 20$ of $\% 20$ entrepreneurial $\% 20$ competencies $\% 20$ on $\% 20$ business $\% 20$ performance $\% 20$ a mong\%20early\%20stage\%20entrepreneurs\&ved=0ahukewij2roiyi_kahxhgy4khxisalw4fbawccew aw\&usg=afqjengp42wsn2yo0bv3szojyrhu5etatq

[9] Bendary A. N. and Minyawi E. A. (2015), Entrepreneurial Competencies effect on Small and Medium Enterprises Performance through the mediation effect of Psychological Contracting of Outsourcing, International Journal of Business, and Economic Development, 3(2).

[10] Lazar N. and Paul G. (2015), Entrepreneurial Competencies in a Business Enterprise- An Overview, International Journal of Scientific Research, 4(1).

[11] Tehseen S. and Ramayah T. (2015), Entrepreneurial Characteristics and SMEs Business Success: The Contingent Role of External Integration, Mediterranean Journal of Social Sciences, 6(1).

[12] Mohamad R. M. and Sidek S. (2013), The Role of Entrepreneurial Competencies as Mediator in the Relationship between Micro finance and Small Business Growth, Journal of Entrepreneurship and Business, 1(1), pp 21-31.

[13] Sarwoko E. et al. (2013), Entrepreneurial Characteristics and Competency as determinants of Business Performance in SMEs, IOSR Journal of Business and Management, 7(3), pp 31-38.

[14] Laguna M., Wlechetek M. and Tallk W. (2012), the Competencies of Managers and Their Business Success, Central European Business Review, 1(3).

[15] Sanchez J. (2012), The Influence of Entrepreneurial Competencies on Small Firm Performance, RevistaLatinoamericana de Psicologia, 44 (2), pp 165-177.

[16] Abdulwahab H. M. and Al-Damen A. R. (2015), The Impact of Entrepreneur's Characteristics on Small Business Success at Medical Instruments Supplies Organizations in Jordan, International Journal of Business and Social Science, 6(8).

[17] Aliyu S. M., Rogo B. H. and Mahmood R. (2015), Knowledge Management, Entrepreneurial Orientation and Firm Performance: The Role of Organizational Culture, Asian Social Science, $11(23)$

[18] Antwi K. S., Inusah M. A. and Hamza K. (2015), the Effect of Demographic Characteristics of Small and Medium Entrepreneurs on Tax Compliance in the Tamale Metropolis, Ghana, International Journal of Economics, Commerce and Management, 3(3).

[19] Isaga N. (2015), Owner- Managers' Demographic Characteristics and the Growth of Tanzanian Small and Medium Enterprises, International Journal of Business and Management, 10(5).

[20] Miao C. (2015), Individual Traits and Entrepreneurial Intentions: The Mediating Role of Entrepreneurial Self-Efficacy and Need for Cognition, Retrieved on January 03,2016 from https://www.google.co.in/url?sa=t\&source=web\&rct=j\&url=http://scholarscompass.vcu.edu/cgi/v iewcontent.cgi\%3farticle\%3d4918\%26context\%3detd\&ved=0ahukewin74ji443kahunci4khciocve 4mhawcbgwaa\&usg=afqjeng-bicuitxixvxwwen42ekxtnnolq

[21] Bakar A. H., Mahmood R. and Ismail H. N. N. (2014), Combined Effect of Knowledge Management and Entrepreneurial Orientation on Performance of Small and Medium Enterprises, Knowledge Management International Conference.

[22] Chuluunbaatar E. et al. (2011), The Entrepreneurial Start-Up Process: The Role of Social Capital and the Social Economic Condition, Asian Academy of Management Journal, 16(1), pp 43-71.

[23] Tamizharasi G. and Panchanatham N. (2010), an Empirical Study of Demographic Variables on Entrepreneurial Attitudes, International Journal of Trade, Economics, and Finance, 1(2).

[24] Hundera B. M. (2014), Micro and Small Scale Enterprises (MSEs) Development Services in Women's Entrepreneurial Start-Ups in Ethiopia: A Study Conducted in three cities: Dire Dawa, Harar and Jigjiga, Journal of Behavioural Economics, Finance, Entrepreneurship, Accounting and Transport, 2(4), pp 77-88.

[25] Iyiola O. and Azuh D. (2014), Women Entrepreneurs as Small- Medium Enterprise (SME) operators and their Roles in Socio-Economic development in Ota, Nigeria, International Journal of Economic, Business and Finance, 2(1), pp 1-10.

[26] Kalitanyi V. and Visser K. (2014), Migration and Migrants Entrepreneurial Skills in South Africa: Assets or Liabilities, Mediterranean Journal of Social Sciences, 5(14). 
[27] Ali H. A. and Ali S. Y. A. (2013), Challenges and Constraints Faced by Somali Women Entrepreneurs in Benadir Region, Interdisciplinary Journal of Contemporary Research in Business, 5(2).

[28] Chitra M et al. (2014), Influence of Personal Factors on Women Entrepreneurs for Success in Beauty Salon Industry, International Journal of Information Technology \& Computer Science, 15(1).

[29] Ongachi N. R. and Bwisa M. H. (2013), Factors Influencing Growth of Women Owned Micro and Small Enterprises: A Survey of Kitale Municipality, International Journal of Academic Research in Business and Social Sciences, 3(10).

[30] Chea C. A. (2008), Factors that Influence the Survival of Women-Owned Small Business StartUps in the city of Tema, Ghana, International Business Research, 1(3).

[31] Yen M. W., Teoh, Choy S., and Chong (2007), Theorizing a Framework of Factors influencing Performance of Women Entrepreneurs in Malaysia, Journal of Asia Entrepreneurship and Sustainability, 3(2).

[32] Olabisi, Yusuff S., Olagbemi A. A. and Atere A. A. (n.d), Factors Affecting Small- Scale Business Performance in Informal Economy in Lagos State-Nigeria: A Gendered Based Analysis, retrieved on January 2, 2016 from https://www.google.co.in/url?sa=t\&source=web\&rct=j\&url=http://www.ilo.org/public/english/iir a/documents/congresses/regional/lagos2011/5thsession/session5a/smallscaleent.pdf\&ved=0ahuke wiwt7eo7irkahuxa44khcjycreqfggemaa\&usg=afqjenfyxa7bbmqhh4t7ac46s_q133iuag

*Corresponding author.

E-mail address: mahadallecc@gmail.com 